\title{
FORMAÇÃO DE PROFESSORES EM TEMPOS DA MATEMÁTICA MODERNA: uma proposta de investigação histórica
}

\author{
Theacher education in modern mathematics time: \\ bistorical questions to investigate
}

\author{
Maria Cecília Bueno Fischer
}

Universidade do Vale do Rio dos Sinos - UNISINOS. Integrante do GHEMAT. São Leopoldo, RS - Brasil, e-mail: ceciliafischer@terra.com.br

\section{Resumo}

O estudo propõe questões de investigação acerca das ações voltadas à formação de professores ao tempo do Movimento da Matemática Moderna, desenvolvidas por três dos grupos de estudo que atuaram no Brasil nas décadas de 60 e 70 . Constitui-se num estudo inicial, que pretende investigar, histórico-comparativamente, aspectos relacionados aos trabalhos desenvolvidos pelos grupos GEEM, NEDEM e GEEMPA, que atuaram, respectivamente, nos estados de São Paulo, Paraná e Rio Grande do Sul.

Palavras-chave:Matemática moderna; Grupos de estudo; Formação de professores.

\section{Abstract}

The text aims to discuss an initial investigation about teacher education, related to the Modern Mathematics Movement, developed by three groups that were active in the field in Brazil 
during the 1960's and 1970's. The research focuses a comparative and historic study between the following groups: GEEM, NEDEM and GEEMPA. These study groups acted, respectively, in São Paulo, Paraná and Rio Grande do Sul.

\section{Keywords: Modern mathematics; Studies group; Teacher education.}

Como integrante do GHEMAT, ${ }^{1}$ venho focando meus estudos sobre a formação de professores ao tempo da Matemática Moderna. Tenho investigado, conforme apontam alguns trabalhos (FISCHER, 2006; FISCHER; CARPES, 2006, 2007), as ações que o Grupo de Estudos sobre o Ensino de Matemática de Porto Alegre, o GEEMPA, ${ }^{2}$ desenvolveu na década de 1970, tais como a elaboração e proposição de cursos para professores do ensino primário e do secundário, além da experiência realizada com classes experimentais em escolas da região de Porto Alegre, no Rio Grande do Sul.

Algumas dissertações desenvolvidas acerca do MMM no Brasil (BÚRIGO, 1989; SOUSA, 1998; SOARES, 2001; LIMA, 2006) mostram que grupos de estudo, organizados em diferentes estados brasileiros, tiveram papel fundamental na disseminação do Movimento, em especial na realização de cursos de capacitação de professores. Destacaram-se: o pioneiro GEEM, Grupo de Estudos do Ensino da Matemática, criado em 1961 na cidade de São Paulo; o NEDEM, Núcleo de Estudos e Difusão do Ensino de Matemática, criado em $1962 \mathrm{em}$ Curitiba-PR; o GEEMPA, já citado, fundado em 1970 em Porto Alegre-RS.

O presente estudo, em desenvolvimento, intenta compreender que ações, direcionadas à formação de professores da Educação Básica, foram desenvolvidas no Brasil, para auxiliá-los a lidar com a "nova" Matemática, surgida a partir do MMM. O foco situa-se nos trabalhos desenvolvidos pelos Grupos anteriormente citados, considerando os contextos em que tais ações ocorreram e levantando indagações que possam contribuir para um estudo comparativo entre os mesmos.

Grupo de Pesquisa de História da Educação Matemática (www.ghemat.mat.br), coordenado pelo prof. Wagner Valente, São Paulo, Brasil.

2 Fundado em 1970, o GEEMPA tinha como preocupação a melhoria do ensino da Matemática. Em 1983, passou a constituir o Grupo de Estudos sobre Educação, Metodologia de Pesquisa e Ação, mantendo a mesma sigla, mas tendo por finalidade o estudo, a pesquisa e a ação para o desenvolvimento das ciências da educação.

Rev. Diálogo Educ., Curitiba, v. 8, n. 25, p. 663-674, set./dez. 2008 


\section{Algumas referências sobre o tema}

Como apontam vários trabalhos já realizados sobre a temática do Movimento da Matemática Moderna (MMM), as discussões acerca de uma nova abordagem para o ensino da Matemática, advindas do Movimento, propunham mudanças que buscavam aproximar o ensino desta disciplina, realizado na escola, ao que era desenvolvido na Universidade, inserindo tópicos como a teoria de conjuntos e estruturas algébricas, topológicas e de ordem. Um grupo que teve influência significativa no MMM, tanto no Brasil como em outros países, foi o assim intitulado grupo Bourbaki, de matemáticos franceses. Alguns matemáticos integrantes desse grupo estiveram em São Paulo, na década de 40, e influenciaram professores que, anos mais tarde, passam a ser figuras importantes na divulgação da Matemática Moderna no Brasil. Entre eles, Osvaldo Sangiorgi, Jacy Monteiro, Omar Catunda e Benedito Castrucci.

Para se compreender o contexto brasileiro, de aceitação da modernização do ensino de Matemática como componente de uma modernização mais ampla da sociedade brasileira, consideramos o que aponta Búrigo (2006, p. 38):

No Brasil, o avanço da industrialização, com a instalação de um setor voltado para a produção de bens de capital e de bens de consumo duráveis, sustentava as expectativas de inserção - ainda que tardia - do país na rota do desenvolvimento. Se a modernização da economia não vinha, como nos países centrais, acompanhada de uma ampla democratização de seus benefícios, acenava com perspectivas de ascensão social - por meio da escolarização e das carreiras técnicas - que encontravam ressonância entre as camadas médias urbanas.

Búrigo (2006, p. 45) nos auxilia, também, na compreensão do alcance do MMM no Brasil, que, segundo ela, pode ser atribuído, em parte, à ressonância de alguns componentes do discurso veiculado: a valorização do ensino de Matemática como indispensável à formação científica e técnica e a conciliação propugnada entre uma Matemática mais avançada e, ao mesmo tempo, mais acessível, respaldada pela participação de professores universitários e secundários no movimento.

Desde 1987, algumas teses e dissertações tem analisado a Matemática Moderna sob diversas abordagens. Destaco algumas delas, que trazem alguma contribuição à temática da formação de professores à época do Movimento.

A tese de Beatriz D'Ambrósio, a primeira pesquisa sobre o MMM no Brasil, apresentada em 1987, analisa o processo de transferência do currículo de Matemática Moderna da América do Norte para o Brasil. A autora aponta

Rev. Diálogo Educ., Curitiba, v. 8, n. 25, p. 663-674, set./dez. 2008 
que, no Brasil, a reforma no currículo pretendia enfatizar o aluno como centro do processo de aprendizagem, ficando o professor com o papel de guia das descobertas do aluno. Conclui, no entanto, que prevaleceram a memorização e a ênfase na linguagem, sem ter havido mudanças quanto à concepção de Matemática entre alunos e professores (PINTO et al., 2007).

Elisabete Búrigo (1989) examina, em sua dissertação, a dinâmica do MMM no Brasil e as visões de seus protagonistas, incluindo discussão e análise do contexto histórico do MMM no país. Detalhando o objetivo de sua investigação, Búrigo levanta um conjunto de questões relacionadas à proposta de inovação do ensino da Matemática difundida pelo Movimento. Embora faça referência a outros grupos, o trabalho abarca especialmente as ações do GEEM, de São Paulo.

Na dissertação de Gilda Delgado de Souza (1998), encontramos referência à participação de professores em cursos de extensão, relativos à Matemática Moderna, e a criação de um grupo de estudos na cidade de Santos, com forte vinculação ao GEEM paulista.

Relatando como foi a implantação e o desenvolvimento do MMM no Brasil, Flávia dos Santos Soares (2001) apresenta experiências bem sucedidas com a Matemática Moderna, desenvolvidas em escolas do Rio de Janeiro na década de 70 .

Alex Sandro Marques (2005), em sua dissertação, trata de como estava estruturada a Matemática escolar no período que antecedeu o MMM no Brasil, auxiliando-nos a compreender o cenário da época que, segundo o autor, não parecia clamar por mudanças.

Em 2006, Flainer Rosa de Lima apresenta sua dissertação, em que analisa cursos realizados pelo GEEM em São Paulo, durante o MMM, destinados a professores de Matemática do ensino secundário. Nas conclusões deste trabalho, a autora aponta a característica tecnicista dos cursos de capacitação de professores realizados por aquele Grupo de Estudos.

As investigações, aqui resumidamente apontadas, precisam ser estudadas, conforme salienta Valente (2006, p. 30), "a partir da análise das transformações ocorridas nas culturas escolares que, por sua vez, sofrem a ação de um movimento internacional de reforma do ensino de matemática." Em particular, no caso deste estudo, com o foco nas ações de formação dos professores, desenvolvidas na época do Movimento. Um fator importante a considerar foi a forte disseminação da política desenvolvimentista desencadeada pelo governo militar da época, que teve implicações nas práticas escolares daquele período.

Rev. Diálogo Educ., Curitiba, v. 8, n. 25, p. 663-674, set./dez. 2008 


\section{Os trabalhos dos grupos GEEM, NEDEM e GEEMPA, nas pesquisas já desenvolvidas: alguns destaques \\ O GEEM}

Segundo os trabalhos referidos, o GEEM foi pioneiro no Brasil quanto à disseminação das idéias do MMM, bem como nas ações de formação de professores para lidarem com a 'nova' Matemática surgida então. Criado em 1961, é esse Grupo que encaminha, no IV Congresso Brasileiro do Ensino da Matemática, ocorrido em Belém do Pará, 1962, proposições de programas de Matemática para a escola secundária, que são aprovadas no evento (BÚRIGO, 1989, 2006; SILVA, 2006).

Conforme registra Lima (2006, p. 49), o GEEM teve como "centro das atenções o MMM e a sua introdução na escola secundária e, num segundo momento, nas escolas primárias e isto se evidenciava no discurso de seus cursos, palestras e livros-texto para professores."

Embora a preocupação mais evidente nos cursos do GEEM estivesse situada no conteúdo matemático, havia experiências voltadas à questão metodológica, realizadas em algumas escolas, que contavam com professores engajados no Movimento.

Destaco, também, alguns aspectos relacionados ao trabalho do GEEM, apontados por Búrigo (2006, p. 45):

O apelo do discurso do GEEM vinha, em parte, de sua condição de grupo de professores, autônomo em relação aos governos. Não se tratava de mais um programa de ensino redigido em gabinete ou imposto por uma escola às demais. A incorporação de elementos da matemática moderna pelas propostas curriculares oficiais foi precedida de muitos encontros e cursos de formação de professores, de participação voluntária e até mesmo militante.

Além disso, Búrigo (2006) salienta que a relativa autonomia do movimento, capitaneado pelo GEEM, não impediu seu aceite e, até mesmo, o incentivo pelos governos autoritários vigentes a partir de 1964 no país, período caracterizado por repressão ao debate educacional e as experiências pedagógicas inovadoras.

Na opinião de D’Ambrósio, citado por Borges (2005, p. 181), o GEEM adotou estratégias "para que as mudanças ocorressem rapidamente e de forma homogênea, quando não era um procedimento ideal, devido às diferenças existentes, em cada localidade, em cada escola." Além disso, em

Rev. Diálogo Educ., Curitiba, v. 8, n. 25, p. 663-674, set./dez. 2008 
sua opinião, as propostas dos cursos ministrados pelo GEEM eram muito formais, rígidas, diferente do que ele propunha, de uma matemática mais instrumental (BORGES, 2005).

As referências acima foram destacadas em função das contribuições que podem dar às análises acerca das ações de formação de professores desencadeadas pelo GEEM.

\section{O NEDEM}

O Núcleo de Estudos e Difusão do Ensino da Matemática NEDEM, criado em 1962, em Curitiba, Paraná, teve papel marcante na disseminação das idéias do MMM no Estado do Paraná, nas décadas de 60 e 70. Conforme destacam Pinto e Ferreira (2006, p. 121), é preciso ressaltar que:

A união, a persistência, a vontade de mudar, de modificar o ensino que tradicionalmente era proposto para os alunos, o espírito de equipe liderado pelo fundador do grupo paranaense foi o ponto forte que conseguiu manter os professores paranaenses de Matemática envolvidos, durante duas décadas, com a proposta moderna de ensino de Matemática.

Ainda segundo Pinto e Ferreira (2006, p. 121), a ações do NEDEM favoreceram a participação dos professores, envolvendo-os nas propostas de reformulação curricular, além da presença em cursos e palestras, "imprimindo novos rumos à história da educação matemática paranaense", levando as escolas a alterarem seus currículos, propondo novos conteúdos ainda não trabalhados. Ainda, acrescentam Pinto e Ferreira, "os componentes do NEDEM tentaram aliar o ensino básico às escolas normais e faculdades, cuidando da formação acadêmica dos futuros mestres" (PINTO; FERREIRA, 2006, p. 120).

Apesar da divulgação intensa propiciada pelo NEDEM, que se deu também por meio da organização e publicação de livros didáticos, nem todos os professores das redes municipal e estadual foram atingidos. "Muitas faculdades do interior não estavam preparando os professores para trabalhar esses conteúdos, dificultando, assim, o sucesso da nova reformulação", apontam as autoras (PINTO; FERREIRA, 2006, p. 120). Esta consideração sugere que o trabalho realizado pelo NEDEM necessitava de uma continuidade relativamente à formação dos professores, que deveria ser propiciada pelos cursos superiores, especialmente no interior do Estado do Paraná.

Rev. Diálogo Educ., Curitiba, v. 8, n. 25, p. 663-674, set./dez. 2008 


\section{O GEEMPA}

Fundado em 1970, o GEEMPA teve sua criação a partir de um grupo de professores preocupados com a melhoria do ensino e da aprendizagem da Matemática, período em que a Matemática Moderna já se fazia presente nos livros didáticos e em discussões em nível nacional. Em 1966, já havia ocorrido um curso de formação de professores de 'Matemática Moderna' no Instituto de Educação, escola de Porto Alegre onde se realizou a assembléia de fundação do Grupo, cujos professores já apresentavam uma trajetória profissional com participação efetiva no MMM e que vai se refletir nos trabalhos produzidos pelo Grupo a partir de sua fundação (FISCHER, 2006).

Várias ações, voltadas à formação de professores, tanto do ensino primário como do secundário, foram realizadas pelo Grupo, como encontros, palestras, reuniões de estudo e seminários.

O GEEMPA enfatizou, desde o início de seus trabalhos, os aspectos metodológicos da renovação do ensino, tendo sido beneficiário da experiência com a Matemática Moderna já desenvolvida em São Paulo (BÚRIGO, 1989).

Conforme destaca Búrigo (1989, p. 140), o GEEMPA, sem romper com a proposta da Matemática Moderna, "seguiu um caminho que se distanciava da origem do movimento, conservando dele o que era um elemento central da proposta de Dienes: a ênfase nos aspectos estruturais envolvidos nos diferentes tópicos". Zoltan Dienes esteve presente em Porto Alegre por diversas vezes, orientando estudos e experiências realizadas pelo Grupo. Muitos anos depois, a professora Esther Grossi, grande incentivadora e uma das figuras de maior influência em toda a trajetória do GEEMPA, assim se manifesta:

Dienes criava atividades relativas a aspectos importantes da matemática, fora dos programas oficiais, mas o que era surpreendente na sua visão era a capacidade e utilizar complexas estruturas matemáticas com alunos muito jovens e obter um grau muito grande de resultados positivos. (GROSSI, 2005, p. 13).

Complementa, ainda, a professora Esther: "Dienes repetia a maneira convencional de desenvolver a aprendizagem da matemática, tendo como fim das referidas aprendizagens a formalização axiomática e o apoio na lógica dos conteúdos ensinados" (GROSSI, 2005, p. 14), salientando que o destaque estava mais no conteúdo matemático do que, propriamente, no processo de aprendizagem dos alunos.

Rev. Diálogo Educ., Curitiba, v. 8, n. 25, p. 663-674, set./dez. 2008 


\section{As questões a responder}

Os apontamentos aqui apresentados, sobre os três grupos de estudo que tiveram destaque no Brasil, ao tempo da Matemática Moderna, foram trazidos como uma primeira tentativa de aproximação entre eles. Necessitam ser revisitados e complementados, na busca de mais elementos que possam favorecer um estudo comparativo entre as ações desenvolvidas por seus atores em cada Estado.

$\mathrm{O}$ que se pode indagar, preliminarmente? Alguns aspectos despontam, num olhar inicial sobre o que já se investigou sobre os três Grupos:

- Quais e como foram as apropriações, em cada Grupo, das tendências internacionais acerca do MMM? Como isso se reflete nas ações de formação dos professores secundários?

- De que forma o racionalismo tecnicista, da então política vigente, interferiu nas ações de formação ou "capacitação" docente, desenvolvidas nos Grupos?

- De que forma os professores recebiam as idéias da Matemática Moderna, veiculadas por meio das ações dos Grupos?

- De quem era a iniciativa quanto à participação nas atividades propostas pelos Grupos?

- O que cada Grupo privilegiou: o conteúdo ou a metodologia de ensino da Matemática Moderna?

- Que influências sofreram, entre si, os três Grupos?

\section{Base teórico-metodológica}

O estudo em questão fundamenta-se nas contribuições da história cultural e apóia-se em Certeau (1982) para a compreensão de alguns conceitos fundamentais como: objetos culturais, sujeitos e práticas.

Conceituando história como uma prática cultural, Certeau emprega a palavra história no sentido de historiografia que, no seu entender, significa: uma prática (uma disciplina), o seu resultado (o discurso) ou a relação de ambos sob a forma de uma produção (CERTEAU, 1982, p. 32). Para este historiador, a história é uma operação que faz parte da realidade da qual se trata e que pode ser apropriada enquanto atividade humana, enquanto prática.

As práticas escolares de Matemática Moderna, compreendidas como práticas discursivas da escola, expressam "não só uma gramática escolar, mas também o que a escola daquele período privilegiou como conhecimento matemático moderno e necessário para a formação científica da população

Rev. Diálogo Educ., Curitiba, v. 8, n. 25, p. 663-674, set./dez. 2008 
escolarizada" (PINTO et al., 2007). As recentes pesquisas desenvolvidas acerca do MMM, fundamentadas na perspectiva histórico-cultural, evidenciam as múltiplas apropriações do ideário desse Movimento em diferentes espaços/tempos escolares.

Chervel (1990, p. 184) chama a atenção para o papel importante da história das disciplinas escolares na história da educação e, mais ainda, na história cultural, desde que se reconheça que uma disciplina escolar comporta "não somente as práticas docentes da aula, mas também as grandes finalidades que presidiram sua constituição e o fenômeno de aculturação de massa que ela determina." Ao focarmos o estudo sobre a formação de professores da disciplina Matemática, interessa considerar, também, como se deu o ensino dessa disciplina, pois, como aponta Chervel (1990, p. 191), "no coração do processo que transforma as finalidades em ensino, há a pessoa do docente." Segundo o autor:

Apesar da dimensão 'sociológica' do fenômeno disciplinar, é preciso que nos voltemos um instante em direção ao indivíduo: como as finalidades the são reveladas? Como ele toma consciência ou conhecimento delas? E, sobretudo, cada docente deve refazer por sua conta todo o caminho e todo o trabalho intelectual que levam as finalidades ao ensino? (CHERVEL, 1990, p. 191).

Para se ter conhecimento das reais finalidades da escola, é preciso voltar-se à realidade pedagógica, além dos objetivos definidos em documentos e outros materiais, produzidos em cada época sobre a escola (CHERVEL, 1990). Como tais finalidades chegam aos docentes? Segundo o autor, é por meio de uma tradição pedagógica e didática complexa, na verdade, sofisticada e minuciosa.

Julia (2001, p. 19) reforça, também, a importância de se voltar às práticas escolares, ao cotidiano da escola. Conforme destaca, "é nos tempos de crise e de conflitos que podemos captar melhor o funcionamento real das finalidades atribuídas à escola." Este parece ser o caso do MMM, constituído como um tempo de mudanças no ensino de Matemática a partir de uma discussão internacional.

As ações desenvolvidas pelos professores permearam os contextos escolares, marcando historicamente a cultura escolar nesse determinado tempo. Para compreender cultura escolar, recorremos a Julia (2001, p. 10), que a conceitua como:

[...] um conjunto de normas que definem conhecimentos a ensinar e condutas a inculcar, e um conjunto de práticas que permitem a transmissão desses conhecimentos e a incorporação desses conhecimentos; normas e práticas coordenadas a finalidades que podem variar segundo as épocas (finalidades religiosas, sociopolíticas ou simplesmente de socialização).

Rev. Diálogo Educ., Curitiba, v. 8, n. 25, p. 663-674, set./dez. 2008 
Ao se analisar as normas e práticas da cultura escolar, é preciso levar em conta os profissionais responsáveis por aplicá-las: os professores. São eles que são chamados a obedecer às ordens das normas e práticas e, "portanto, a utilizar dispositivos pedagógicos encarregados de facilitar sua aplicação" (JULIA, 2001, p. 11).

No nosso estudo, interessa-nos tanto os saberes como as práticas escolares como integrantes da cultura escolar, pois focamos as ações de formação de professores de uma disciplina específica do currículo escolar: a matemática.

O desafio de realizar um estudo histórico-comparativo é grande, considerando as diversas dificuldades aí envolvidas, como aponta Nunes (2001, p. 58), tais como: eleger os aspectos da comparação; lidar com uma grande massa de dados primários quase sempre desequilibrados e a necessidade de manusear uma enorme bibliografia secundária construída com diferentes objetivos e posturas teóricas. Nesse sentido, Valente, citando Marcel Detienne, aponta a necessidade de construir comparáveis, o que implica "em considerar como campo de exercício e de experimentação o conjunto das representações culturais entre sociedades do passado, tanto as mais distantes como as mais próximas" (DETIENNE, 2000 apud VALENTE, 2006, p. 25).

Acredita-se que o estudo do Movimento da Matemática Moderna, sob os diferentes enfoques - as ações de formação de professores, no caso deste estudo - constitui um tema precioso para a produção de novos conhecimentos a partir da história comparativa.

\section{REFERÊNCIAS}

BORGES, R. A. S. A matemática moderna no Brasil: as primeiras experiências e propostas de seu ensino. 2005. 204 f. Dissertação (Mestrado em Educação Matemática) - Pontifícia Universidade Católica de São Paulo, São Paulo, 2005.

BÚRIGO, E. Z. Movimento da Matemática Moderna no Brasil: estudo da ação e do pensamento de educadores matemáticos nos anos 60. 1989. 208 f. Dissertação (Mestrado em Educação) - Universidade Federal do Rio Grande do Sul, Porto Alegre, 1989.

O Movimento da Matemática Moderna no Brasil: encontro de certezas e ambigüidades. Revista Diálogo Educacional, Curitiba, PR, v. 6, n. 18, p. 35-47, maio/ago. 2006.

CERTEAU, M. de. A escrita da história. Tradução de Maria de Lourdes Menezes. Rio de Janeiro: Forense Universitária, 1982.

Rev. Diálogo Educ., Curitiba, v. 8, n. 25, p. 663-674, set./dez. 2008 
CHERVEL, A. A história das disciplinas escolares: reflexões sobre um campo de pesquisa. Teoria \& Educação, Porto Alegre, RS, n. 2, p. 177-229, 1990.

FISCHER, M. C. B. A experiência das classes-piloto organizadas pelo GEEMPA, ao tempo da Matemática Moderna. Revista Diálogo Educacional, Curitiba, PR, v. 6, n. 18, p. 101-112, maio/ago. 2006.

FISCHER, M. C. B.; CARPES, F. O acervo do GEEMPA como fonte para a escrita da história da educação matemática em Porto Alegre, ao tempo da matemática moderna. In: SEMINÁRIO TEMÁTICO: A MATEMÁTICA MODERNA NAS ESCOLAS DO BRASIL E DE PORTUGAL: ESTUDOS HISTÓRICOS COMPARATIVOS, 2006, 1. São Paulo. Resumos... São Paulo: GHEMAT/PUC-SP, 2006.

Reformulação metodológica do ensino da matemática no $1^{\circ}$ grau: análise preliminar do relatório de pesquisa realizada pelo GEEMPA (1975). In: MATOS, J. M.; VALENTE, W. R. (Org.). A matemática moderna nas escolas do Brasil e de Portugal: primeiros estudos. São Paulo: Da Vinci/CAPES, 2007. p. 123-135.

GROSSI, E. P. Uma arqueologia dos saberes do GEEMPA. Revista GEEMPA (35 anos), Porto Alegre, n. 10, p. 11-39, set. 2005.

JULIA, D. A cultura escolar como objeto histórico. Revista Brasileira de História da Educação, Campinas, SP, n. 1, p. 9-43, jan./jun. 2001.

LIMA, F. R. Grupo de estudos do ensino da matemática e a formação de professores durante o Movimento da Matemática Moderna no Brasil - GEEM. 2006. 131 f. Dissertação (Mestrado em Educação Matemática) - Pontifícia Universidade Católica de São Paulo, São Paulo, 2006.

MARQUES, A. S. Tempos pré-modernos: a matemática escolar dos anos 50. 2005. 150 f. Dissertação (Mestrado em Educação Matemática) - Pontifícia Universidade Católica de São Paulo, São Paulo, 2005.

NUNES, C. História da educação e comparação: algumas interrogações. In: Sociedade Brasileira de História da Educação (Org.). Educação no Brasil: história e historiografia. Campinas, SP: Autores Associados; São Paulo: SBHE, 2001, p. 53-71.

PINTO, N. B.; FERREIRA, A. C. C. O movimento paranaense de matemática moderna: o papel do NEDEM. Revista Diálogo Educacional, Curitiba, PR, v. 6, n. 18, p. 113-122, maio/ago. 2006.

Rev. Diálogo Educ., Curitiba, v. 8, n. 25, p. 663-674, set./dez. 2008 
PINTO, N. B. et al. História do Movimento da Matemática Moderna no Brasil: arquivos e fontes. Guarapuava, PR: Sociedade Brasileira de História da Matemática, 2007.

SILVA, M. C. L. Movimento da Matemática Moderna: possíveis leituras de uma cronologia. Revista Diálogo Educacional, Curitiba, PR, v. 6, n. 18, p. 49-63, maio/ago. 2006.

SOARES, F. S. Movimento da Matemática Moderna no Brasil: Avanço ou Retrocesso? 2001. 192 f. Dissertação (Mestrado em Matemática Aplicada) - Pontifícia Universidade Católica do Rio de Janeiro, Rio Janeiro, 2001.

SOUZA, G. L. D. Três décadas de educação matemática: um estudo de caso da Baixada Santista no período de 1953 - 1980. 1998. 299 f. Dissertação (Mestrado em Educação Matemática) - Universidade Estadual de São Paulo, Rio Claro, SP, 1998.

VALENTE, W. R. A matemática moderna nas escolas do Brasil: um tema para estudos históricos comparativos. Revista Diálogo Educacional, Curitiba, PR, v. 6, n. 18, p. 19-34, maio/ago. 2006.

Recebido: 28/05/2008

Received: 05/28/2008

Aprovado: 01/07/2008

Approved: 07/01/2008 